\title{
Operating on lungs and thinking on hearts
}

\author{
Gonzalo Varela, MD, PhD
}

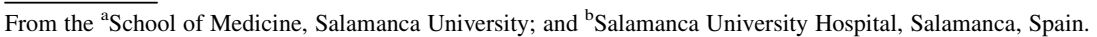
Disclosures: Author has nothing to disclose with regard to commercial support.

Received for publication March 20, 2017; accepted for publication March 21, 2017; available ahead of print April $14,2017$.

Address for reprints: Gonzalo Varela, MD, PhD, Salamanca University Hospital, Paseo de San Vicente 58, 37007

Salamanca, Spain (E-mail: gvs@usal.es).

J Thorac Cardiovasc Surg 2017;154:358-9

$0022-5223 / \$ 36.00$

Copyright (C) 2017 Published by Elsevier Inc. on behalf of The American Association for Thoracic Surgery

http://dx.doi.org/10.1016/j.jtcvs.2017.03.096

The article by Sandri and colleagues ${ }^{1}$ in this issue of the Journal conveys an important message to all of us: Patients with coronary artery disease (CAD) who experience major cardiac complications after videoassisted thoracoscopic lobectomy have a 5-fold higher risk of 30-day mortality compared with patients without CAD (5\% vs $0.9 \%$, respectively). In the authors' experience, this occurred despite similar figures of pulmonary volumes and carbon monoxide lung diffusion capacity (DLCO) in both subsets of patients, meaning that the most frequently reported risk-related parameters are not useful for patients with CAD who undergo pulmonary lobectomy. The authors rightly underline the need of improving perioperative management, starting from more accurate preoperative risk evaluation, but which parameters should we measure in those cases? The immediate postoperative period of patients in whom 1 pulmonary lobe is removed, even if they undergo minimally invasive techniques, encompasses an important physical stress as higher amounts of oxygen are demanded by the body tissues. When 1 of the pulmonary lobes is resected, the blood flow to the remaining lung must be increased by the recruitment of usually closed capillaries in low perfused lung areas. Recruitment can be impaired at peak exercise in patients with mild emphysema if there is arteriosclerotic heart disease and much more in the elderly, those with chronic obstructive pulmonary disease, and sedentary patients in whom capillary blood flow to the muscles is reduced. Preoperative evaluation in these cases should include not only forced spirometry and DLCO at rest but also cardiopulmonary exercise testing to check the patient's functional and metabolic reserve during physical stress. Although measuring the maximal oxygen uptake usually is recommended in selected cases, ${ }^{2}$ an interesting article by Wang and colleagues ${ }^{3}$ published more than 15 years ago and not frequently quoted reported the predictive value of DLCO measured at $70 \%$ of maximal workload. According to the authors, patients failing to increase their DLCO up to a certain level during physical exercise had a higher risk of overall complications and

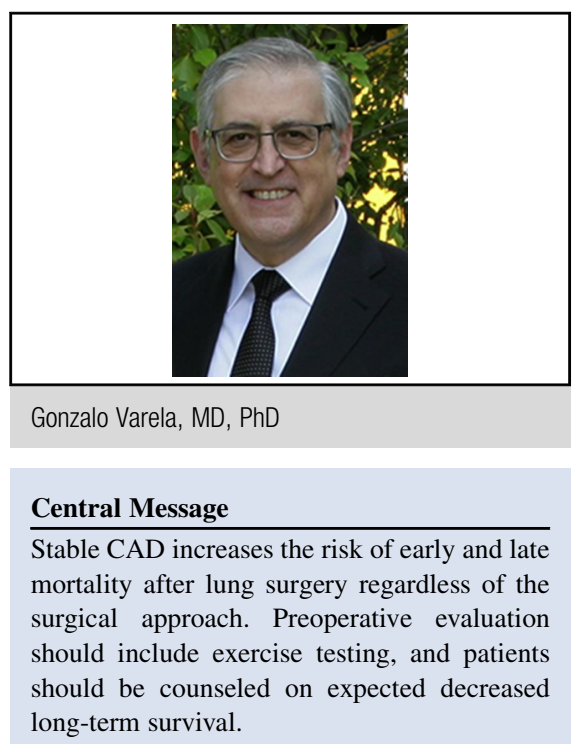

See Article page 352.

cardiopulmonary morbidity. In our settings, we have been able to reproduce Wang and colleagues, 3 observations in a series of cases not selected by cardiac comorbidity (work in progress). Measuring DLCO at peak exercise is less expensive and technically less demanding than measuring maximal oxygen uptake and could be generalized as a screening test in stable CAD cases requiring pulmonary lobectomy.

Knowing the 1-year mortality in the series by Sandri and colleagues ${ }^{1}$ also would be interesting because the reported 30-day mortality in the series probably does not represent the actual risk of the procedure. In a previous article by our team, ${ }^{4}$ we stressed the relevance of measuring all the mortality derived from lung resection and not only death occurring 30 days after. The data presented by Sandri and colleagues $^{1}$ bring to our attention that patients with increased cardiac risk should be counseled about their expected decreased long-term survival after lung surgery regardless of the surgical approach. ${ }^{5}$

\section{References}

1. Sandri A, Petersen RH, Decaluwé H, Moons J, Ferguson MK, Hansen HJ, et al Coronary artery disease is associated with an increased mortality rate following video-assisted thoracosopic lobectomy. J Thorac Cardiovasc Surg. 2017; $154: 352-7$.

2. Brunelli A, Charloux A, Bolliger CT, Rocco G, Sculier JP, Varela G, et al. ERS/ESTS clinical guidelines on fitness for radical therapy in lung cancer patients (surgery and chemo-radiotherapy). Eur Respir J. 2009;34:17-41.

3. Wang JS, Abboud RT, Evans KG, Finley RJ, Graham BL. Role of CO diffusing capacity during exercise in the preoperative evaluation for lung resection. Am J Respir Crit Care Med. 2000;162:1435-44. 
4. Rodríguez M, Gómez MT, Jiménez MF, Aranda JL, Novoa NM, Varela G. The risk of death due to cardiorespiratory causes increases with time after right pneumonectomy: a propensity score-matched analysis. Eur J Cardiothorac Surg. 2013;44:93-7.
5. Brunelli A, Ferguson MK, Salati M, Vigneswaran WT, Jimenez MF, Varela G. Thoracic revised cardiac risk index is associated with prognosis after resection for stage I lung cancer. Ann Thorac Surg. 2015;100:195-200. 